\title{
SUBLIMINAL MESSAGES IN ADVERTISING: DO THEY REALLY WORK?
}

Preliminary communication

UDK: 659.13/.16:179

JEL classification: M31, M37, A13

DOI: 10.17818/DIEM/2022/1.11

Accepted for publishing: July 8, 2021

\begin{abstract}
Subliminal messages appear in movies, commercials, music videos, and even cartoons. These are hidden signals inserted into advertising messages sent to a target audience to influence their subconscious behaviour. Such advertising is often considered unethical and, in certain types of advertising, even forbidden by law. Most research to date indicates that people do, in some way, perceive subliminal stimuli that can have an impact on their behaviour. Subliminal messages are viral and are used to manipulate consumers. However, most human psyche researchers are still inclined to think people cannot be persuaded on an unconscious level to behave in a way they would not consciously act. How crucial the influence of subliminal messages is for behaviour has not yet been sufficiently explored. The main goal of this paper is to determine whether people are aware of the existence of subliminal messages in the media and media manipulations and do they find them ethical. An online survey was conducted to assess the respondents' awareness, attitudes, and beliefs regarding subliminal advertising. The results show that the understanding of subliminal perception related to instinct and emotion is evident. The contributions will help both; marketing managers when deciding should they use subliminal messages in their advertising and consumers when deciding if they want to purchase a specific product.
\end{abstract}

Keywords: ethics, advertising, subliminal messages

\section{INTRODUCTION}

Nowadays, screens have become time thieves (Towers, Duxbury, Higgins \& Thomas, 2006). Recent researches show that children and young people spend more and more time in front of the computer or mobile screen (Twenge \& Campbell, 2018, Sigman, 2012, van der Voort, Beentjes, Bovill, Gaskell, Koolstra, Livingstone, Marseille, 1998). Therefore, it is not surprising that the number of media addicts, violent scenes, and manipulative content overgrows for past years. The subliminal message first appeared back in 1917, when allusion to sex was included in the news about Norman Rockwell on the cover of the American magazine "The Saturday Post" (Dijksterhuis, Aarts \& Smith, 2005). After that press release, subliminal messages began to appear on film as well. 
In 1957, James Vicary conducted an "Invisible Commercial" experiment at a New Jersey cinema for a full six weeks (Crandall, 2006). Namely, every five seconds of the movie "Picnic", the commercial "Hungry?" Eat popcorn. Drink Coca Cola." message was flashed for 3/1000 of a second once every five seconds. Popcorn sales in that cinema increased by $58 \%$, and Coca Cola sales increased by $18 \%$ compared to the previous six weeks. Today, people are surrounded by different media types, so is the greater spectrum of subliminal messages and their influences on the human subconscious. Subliminal messages did not bypass the radio either. Subliminal messages can also be hidden in relatively simple verbal or musical illusions. They imprint desires in individuals subconscious to influence their decisions and instil specific mental patterns. Most researchers (Vokey, Read, 1985) agree that the topic of subliminal messages is intriguing. Despite numerous findings on the effects of subliminal perception, some people still deny the existence of this phenomenon. This paper attempts to answer several questions; whether idividuals perceive subliminal messages, their attitudes towards them and to what extent they influence their beliefs and behaviour.

\subsection{The subliminal perception}

Subliminal perception is the idea that it can influence someone's thoughts, feelings, and behaviours through various stimuli without the conscious knowledge of the person being affected. The stimuli which the brain consciously receives are called supraliminal stimuli (Weber, 2010.) Subliminal perception fails to reach consciousness, and therefore it cannot be verbalized. This is especially true for children and young people because the younger a person is, the greater is the chance of influencing her behaviour (Miliša and Nikolić, 2013). Even adults in their everyday life cannot recognize all verbal and nonverbal symbols. Media pedagogy must enable the discovery of subliminal stimuli so that young people can distinguish between reality and fiction. Children movies and cartoons are the best examples. Every child is exposed to them. The hidden contents shown in the movies do not have to reach consciousness immediately, and the subliminal perception works invisibly (Tolić, Vertovšek, Miliša, 2009). For example, when children are presented with a visual scene, they consciously see all the details in a particular scene. However, if a small detail change in the background (usually it happens very quickly), they only "process" the difference, but that does not mean they experienced it on a conscious level. Whether the change is processed on a conscious or subconscious level depends on the viewer's attention (Tolić, Vertovšek, Miliša, 2009). Due to the above, it is necessary to analyze various aspects (cultural and educational) of animated movies and other media content. Consumer manipulation happens in all aspects of human lives. Although this is an ethically unacceptable practice, it is used in various areas such as economics, consumer manipulation happens in advertising; in politics, voter manipulation takes the form of indoctrination; in the field of leisure, manipulation takes the state of the entertainment industry.

\subsubsection{The subliminal messages}

The subliminal messages are messages below the limit of individuals perception. The human eye or mind can not perceive them. As much as $89 \%$ of human activity is unconscious, the possibility of influencing that part is significant. Some authors (Egermann, Kopiez \& Reuter, 2006) define subliminal messages as a signal or message inserted into another object. The intention is to bypass the normal boundaries of perception or as "any situation in which unnoticed stimuli are perceived. "(Egermann, Kopiez \& Reuter, 2006). It is a phenomenon that emerged in 1957. when James Vicary, the manager of a local cinema in New Jersey, tried to influence the consumer subconscious as is already described. The experiment was called "Invisible Commercial". The public was against such experiments, so they were no longer conducted, at least not publicly. In an experiment conducted by Krosnick, Betz, Jussim \& Lynn, 1992), the respondents have been presented the slides of nine strangers. They were asked to rate how nice they were to the people in the pictures, but they were shown either an emotionally positive or emotionally negative image before each picture. The 
images flashed very quickly, so the respondents could not consciously notice them. Emotionally positive images showed kittens or a couple in love, and emotionally negative images showed corpses or werewolves. Although they could not consciously perceive these images, the respondents rated people whose pictures were associated with emotionally positive images nicer than others. The people's faces looked more likeable after subliminally presented and consciously unnoticed kittens than if they followed after subliminally presented and consciously unnoticed corpses. The first and oldest example of a subliminal message was referred to as sex. The word "sex "is the most used term and image in subliminal messages. For example, on the Seychelles banknote of 50 rupees, the word "sex" is written in the upper right corner of the palm leaves. It can only be noticed if you look closely. A similar example is noticed in the Disney cartoon "The Lion King", where the word "sex" is written in the sky for just a moment. The word "sex" is also the most used term in advertising products and services. However, consumerism is not the only field of using subliminal messages. They can be found in political campaigns to manipulate the masses, as shown in Ran Hassin studies (Hassin \& Sklar, 2014). Namely, the subliminal display of national symbols, such as flags, influences political attitudes and voters decisions. Although the influence of subliminal messages is still not scientifically proven, their effect on peoples consciousness is without a doubt. The human brain is divided into two halves. The left half of the brain is responsible for the rational and analytical functions of the nervous system. In contrast, the right half is responsible for the subconscious work, emotions and instinct. Thus, the hidden message leaves no trace on the left half of the brain that does not recognize it, but in the right half, it becomes a command. The research conducted by psychologists Strahan, Spencer and Zanna in 2002 explored the influence of subliminal messages on peoples thirstiness. They gathered a group of people and experimented. The respondents had to concentrate on the centre of the screen. They displayed thirsty, dry, and dehydrated words on the screen in a split of a second. The research showed that the messages displayed on the screen had almost no effect on the part of the group which did not feel thirsty. The opposite happened with the group already a little bit thirsty when they came but were told not to drink anything for the next three hours. The research results in this part of the group showed that subliminal messages significantly impacted and intensified the feeling of thirst. As a reward, at the end of the study, all respondents received a glass of juice. This glass of juice was also part of the experiment to test the degree of thirstiness. Some of the people who have already been thirsty drank much more than the others. The research showed that subliminal messages do not have enough power to create specific emotions, intentions, or motivation for changing behaviour. Still, these subconscious messages can be significantly enhanced if people already have some motivation or feeling. Later, in 2006, psychologists Karremans, Stroebe and Claus assumed that subliminal messages could amplify a particular feeling, such as thirst can affect people in terms of standing behind a particular producer. As an example, Lipton iced tea was used for the experiment. The researchers used part of the 2002 study by dividing the respondents into two groups; in the first one, the respondents were thirsty, and in the other, they were not. As in the previous study, respondents were required to focus on the central part of the screen where the Lipton logos and images of their iced tea were displayed separately within three hundredths. At the end of the experiment, the researchers offered the respondents two types of iced tea: Lipton and the other iced tea was from an unknown manufacturer. It has been shown that respondents who were already thirsty preferred Lipton iced tea. The survey confirmed that subliminal messages could not only amplify a particular feeling but have the power to steer people in a particular direction to meet their unsatisfied needs. In 2013, psychologists Gibson and Zielaskowski (2013) researched a Las Vegas casino where they inserted thumbnails showing a US dollar symbol or a jackpot message on second-hand clips on slot machines. Some people who were shown these messages invested 55\% more money on gambling and betting than other people in the casino. Approximately $45 \%$ of respondents were convinced they would win something after being exposed to subliminal messages about winnings. Respondents also reported they felt a purge to invest more money. Researches have shown that the perfect mix of circumstances contributed to the power of subliminal messages. 


\subsubsection{Subliminal advertising}

Subliminal advertising is a technique that exposes the consumer, without their knowledge, to images of products and brands. Once exposed to a subliminal stimulus, the consumer is convinced that they understand the information. The most controversial area within subliminal psychological processes is "subliminal persuasion", which implies the direct influence of subliminal techniques on consumer behaviour. Weber (2010) was interested in finding ways to incorporate subliminal stimuli into advertisements to influence future behaviour. After James Vicary experiment with popcorns and coca-cola, subliminal advertising drew the attention of marketing managers. Since then, many types of research on the effectiveness of subliminal advertising were conducted (Key, 1992). Some aspects of consumer behaviour are imbued with irrationality. The consumer is led by their desires and responds to their influence. In nature, every human being is to express themselves with a brand, and brand somehow becomes part of someone's personality. Why does the consumer buy a specific type of TV? Which factors are crucial during that decision? The price, screen size, style or brand reputation? There are many different brands with hundreds of additional features. However, only one brand sells more TVs than others, considering that some brands have entirely different consumer groups. The same research showed that the final decision takes place only after the consumer has deemed several options. The consumer will always choose a product to which they are more attached. That is why it is essential which product characteristics are taken into account when the consumer chooses between different brands (Miliša \& Nikolić, 2013). It happens under the influence of internal stimuli and stimuli imposed by the media environment (Schiffman, Kanuk \& Fridl, 2004). The emotional content of subliminal stimuli can have different effects on different people. For example, Theus (1994) concluded that neurotic people incline to process words with emotional content rather than neutral words. People who show less repression, more passivity, more flexibility in reporting, and less aggression are more likely to process subliminal stimuli. Research has also shown that if the intensity of subliminal stimuli increases, their effect on a person also increases. The power of the stimulus increases the closer the stimulus is to the supraliminal level. Bornstein, Leone \& Galley (1987) also came to this conclusion. They emphasize that the subject's relationship to the new stimulus becomes more positive after frequent stimulus repetition. The most important thing is that subliminal stimuli must be organized into a system of instincts. That will lead to a more successful application of subliminal techniques since instincts powerfully drive people. What will be perceived from a multitude of external stimuli depends on several factors: relative intensity of stimulus content, quality of that content, time duration, change in movement, content dynamics, content contrast, repetition of stimuli, previous experience, habits, attitudes, motivation, interests, needs and expectations. In 1982, Riggs, Volkmann, Moore \& Ellicott realized that subliminal stimuli could elicit a strong or a weaker reaction. A more assertive response means that subliminal stimuli create instant changes in consumer behaviour. This relationship between subliminal stimulus and brand choice has been explored for decades. Results showed that subliminal advertising could directly affect a consumer's brand choice and changes in future behaviour. Subliminal stimuli can also cause changes in feelings, behaviour, beliefs and instincts. Subliminal stimuli associated with product selection advertisements are called "attention catchers," and particular emphasis is placed on sexual allusions, which are the strongest attention catchers. Subliminal persuasion refers to the presentation of subliminal content by someone who intentionally wants to influence consumers behaviour. Advertisements sell the product, but their main goal is to make products characteristics relevant to the consumer giving them a deeper meaning. Thus products become relevant to consumers, and they start giving them a particular purpose. The information presented in advertisements is not a response to consumer needs. Instead, they urge to impose the requirements which the producer of a specific product wants the consumer to have. 


\subsection{Subliminal influence on consumer behaviour}

Manipulation and indoctrination are not visible to persons who have been manipulated and indoctrinated (Ayrapetova, 2020). In the imposed world of consumerism, consumers easily become targets of persuasion, indoctrination, propaganda, brainwashing and conditioning. The effects of subliminal stimuli are confirmed on many measurable behaviours ranging from brief semantic effects to severe effects on emotions and human behaviour. The boundary between the information consumer consciously receives and those perceived subconsciously (subliminally) is perceptual. It is also influenced by cultural indoctrination. Many experiments revealed that mental tension, anxiety, and understanding of things control the perceptual boundary. As the tension in an individual increase, the person perceives less and less on a conscious level and becomes more susceptible to subliminal stimuli. As tensions decrease, individuals perceive a huge range of information on a conscious level and are thus less susceptible to sublimates. The more an individual tries to perceive sublimates, the less likely they are actually to perceive them. Otto Pötzl, one of Freud's contemporaries, postulated the "law of exclusion" (Ben-Aaron, 1975) and held that the content of dreams included subliminally and subconsciously perceived experiences. He was the first scientist who connected subliminal stimuli and posthypnotic suggestion. The Pretzel effect involves a delayed reaction or, as he calls it, a "time clock" phenomenon. His research has found that subliminal perception can arouse dreams and trigger behaviours for days, even weeks, after initial perception. At the time when individuals perceive a subliminal stimulus, they are still not aware of that perception. These hidden messages often include sex or fear of death, prompting the individual to a delayed reaction. A few weeks later, more susceptible individuals will spot the product in the supermarket. This second conscious perception will serve as a trigger for reaction or action. Dreams have long been considered a product of the subconscious. The contents of dreams in the REM phase, that is, in the deep sleep phase, include only subliminal perceptions. If paired with secondary conscious perception, subliminal perception causes different types of behaviour after a certain time. One of the most potent effects of subliminal stimuli on behaviour involves memory (Moore, 1982). Memory is made up of hormonal, electrical and chemical processes, among relationships that function simultaneously and at high speeds, through billions of microscopic neural systems. Forgetting is, for example, a process in which specific conscious ideas lose their distinctive power, primarily because attention has waned. Forgotten thoughts do not cease to exist. Libet, Alberts, Wright, Delattre, Levin, \& Feinstein (1964) were probably the first to obtain subliminal perception. They stimulated their subjects' skin but subtly so that the subjects did not feel anything. Simultaneously measured evoked potentials showed changes in the electric field of the brain. These measurements provided evidence that brain activity occurred due to perceiving information that did not reach the level of consciousness. Conscious perception is anything that is excluded from the immediate state of consciousness. As tensions decrease, individuals perceive a more excellent range of information at the conscious level. So less susceptible to sublimates. The more an individual tries to perceive sublimates, the less likely they are actually to perceive them. Bargh \& Pietromonaco (1982) have shown that subliminally activated constructs of some human traits or personality traits affect what impressions a person forms about others. In their experiments, subjects were shown flashes (actually words) in different places on the screen and subjects were asked to determine the location of each flash. Depending on the experimental conditions, $0 \%, 20 \%$, or $80 \%$ of the words were associated with aggressiveness traits. Upon completing the task, respondents were presented with a brief description of the person (stimulus) who behaved in an ambiguous hostile manner. The impression that the respondents formed about this person was influenced by their subliminal exposure to these words. The more aggressive the words, the more negative the impression about the person. Respondents did not remember the words displayed during the flash. Subliminal messages are not really hidden, but this hiding is realized by the ones who subconsciously want to hide disturbing information or media images. Thus, free will becomes a myth in the ideology of media seduction. Words that contain emotional messages or words like sex firmly fix their content and label it on a subconscious level. The storage capacities of subliminal perception related to instinct and emotion are evident. Such inserted 
stimuli can remain in the subconscious memory for a longer period, sometimes a lifetime. Subliminals have been shown to affect dreams, memory, level of adjustment, conscious perception, verbal behaviour, emotional reaction, instinct-related behaviours, and perceptual boundary. Subliminal persuasion is most effective in subjects with no firm and well-structured resistance in confronting habits and beliefs. Behaviour and values elicited by subliminal stimuli have similar effects as a posthypnotic suggestion. As in hypnosis, it is challenging for some people to resist instructions they have not consciously experienced, no matter how pointless those instructions may seem. Previous results of selected studies on effects of subliminal acoustical messages (SAM) and subliminal self-help tapes (SHT) showed no affects on individuals behavior (Henley, 1975, Benes, Gutkin, Decker, 1990, Greenwald, Spangenberg, Pratkanis, Eskenazi, 1991, Russell, Rowe, Smouse, 1991, Merikle, Skanes, 1992, Staum, Brotons, 1992, Walls, Taylor, Falzone, 1992, Benoit, Thomas, 1992, Möller, Kotzé, Sieberhagen, 1993, Mitchell, 1995, Moore, 1995, Harris, Salus, Rerecich, Larsen, 1996, Froufe, Schwartz, 2001).

\section{RESEARCH METHOD}

The deductive approach is adopted in order to achieve the objectives of this study.

Within the scope of this research, we were are only interested in answering the research question, which was formulated from a theory of general content; are individuals aware of subliminal messages and do they find them ethical. The sampling was convenience sampling since the population is large. We used the virtual snowball sampling since we used virtual social networks for reaching the respondents. This method was chosen because it's fast, simple, and economical. The survey was sent via social network Facebook and mobile aplication WhatsApp during the period of 30 of April until 15th of May 2021. A survey was send to individuals who then passed it to their contacts until we achieved a satisfactory number of responses.

\subsection{Online survey}

The authors used online surveys to explore whether respondents are aware of subliminal messages and what is their opinion about using them; is it ethical or unethical and do they influence their behaviour. The questionnaire was created on the google forms platform. It was an anonymous online survey. This method was used because it is speedy and inexpensive. An introduction part was presented at the start of the questionnaire to give participants a clear idea of the purpose of the study. This structured questionnaire was adopted from the study of Haber (1959) and Zanot, Pincus and Lamp (1983). The questionnaire was divided into two sections. The first section was about the demographics data and included questions related to gender, age and education level. The second section embraced ten inquiries related to respondents usage of new media and the general knowledge of subliminal messages. The questionnaire consisted of dichotomous questions, Likert scales, and multiple-choice questions selections.

\subsection{Determination of the sample}

There was a total of 510 respondents. $31.2 \%$ of the total respondents (159) were males, and $68.8 \%$ (351) were females. These percentages show that females have a higher interest in filling the questionnaire online. The age of participants varies between 15 and 55 years and older. The majority of the respondents were age between 15 and 24 years (38.9\%), then 35 - 44 years $(22.1 \%)$, $25-34(21.2 \%), 45-54$ (13\%). There were only five respondents older than 54 years. Many studies have found that young adults prefer to respond via the web while older individuals prefer non-web modes (Millar et al., 2009. and Smyth et al., 2014). The results showed that the majority of respondents have a university degree $(69.9 \%)$, secondary school $(27.4 \%)$ and only $(2.7 \%)$ with only 
a primary school diploma. A small effect by education level was found: the higher the education, the higher the overall willingness to participate in research.

\subsection{The empirical results}

The authors surveyed to determine how the public is aware of using the phenomenon of subliminal messages in advertising. Has the public opinion change since Haber conducted the research in 1957? This questionnaire aims to obtain new data about public attitudes and beliefs. When asked which type of the media they regulary (on daily bases) consume most of the respondent indicate they use the Internet daily $(93.8 \%)$, TV $(60.2 \%)$, radio $(29.2 \%)$, daily newspapers (15.9\%). When asked: Do you ever consciously feel influenced by adverts? 54.9\% answered "yes ", $25.7 \%$ answered "no "and $19.5 \%$ answered "not sure ". After this question, respondents were asked to click on the link to watch the video explaining the subliminal messages: https://youtu.be/UHH7zJySTrw (video duration $3.47 \mathrm{~min}$ ). Before accessing this website, have you heard of subliminal advertising before? $81.4 \%$ answered "yes, "18.6\% answered "no". When asked if they think subliminal messages have been used in advertising, 83.2\% answered "yes ", and 15\% answered "not sure ", with only $1.8 \%$ of respondents who answered "no". When asked if they think subliminal messages are used in advertising today, 85.8\% answered "yes, " 8.8\% "not sure," and only 5.3\% answered "no". If they answered this question "yes", they could move to the next question. If not, they were allowed to skip it. When they were asked how frequently the subliminal advertising is used, $2.9 \%$ answered extremely rare, $2 \%$ rarely answered, $21.6 \%$ answered "neither rare or neither frequent", $31.4 \%$ answered "frequent", and $42.2 \%$ answered "extremely frequent". When they were asked if they think subliminal advertising is an ethical or unethical practice, $63.7 \%$ of respondents find it unethical, 31.9\% are "not sure " if it is an ethical or unethical practice ", and only $4.4 \%$ find it ethical. The next question was: If you were watching a television programme and were aware that subliminal messages were embedded in the advertisements, would you continue watching? This remark does not mean you can consciously see the messages; rather, you are aware they are present. Respondents (77\%) answered they would continue watching while $23 \%$ would stop watching TV. Then asked to indicate to what degree they think subliminal messages can affect people's attitudes or beliefs. They answered as follows: no affect at all (2.7\%), $13.3 \%$ slightly affect, $26.5 \%$ were neutral, $37.2 \%$ affect, significant affect (20.4\%). When they were asked to what degree they think subliminal messages can affect people's behaviour, the answers were following; $3.5 \%$ answered that it does not affect at all, $9.7 \%$ slightly affect, $20.4 \%$ were neutral, and $45.1 \%$ slightly, and $21.2 \%$ answered significant effect.

\section{CONCLUSIONS AND RECOMMENDATIONS}

The subliminal messages have been a controversial point widely discussed in the literature. Consumer awareness of subliminal advertising and the degree to which they believe that subliminal messages in media are used to influence people's attitudes, and behaviour are studied. This article gave a deeper insight into subliminal message perception and awareness. Still, there is no clear conclusion regarding the position of respondents according to subliminal messages. However, research confirmed respondents generally negative attitude towards the subliminal advertisements, as already evidenced in numerous studies. The survey found that $81.4 \%$ of the sample had heard of subliminal advertising. That percentage has grown over the decades but not so during past years. For instance, Haber (1959) discovered that $41 \%$ of San Francisco-area residents had heard of subliminal advertising at that time. Zanot, Pincus and Lamp (1983) found that $81 \%$ of their interviewees had heard of subliminal advertising. The percentage has not increased much since. Our study showed approximately $64 \%$ of respondents find it unethical. In addition, $77 \%$ stated they would continue to watch a TV programme, even if they thought subliminal messages were embedded in the commercials. The majority of respondents believe that 
subliminal advertising was frequently used (more than $81 \%$ ), and they believe today they are used even more (84\%). Furthermore, they also think it does influence their behaviour. Results show that most respondents use the Internet (almost 94\%) and watch TV (more than 60\%) daily. The results of all studies indicate that awareness of subliminal messages is very high, belief that it is (often) used runs high, and reactions to their usage are negative. The laws recognize the existence of subliminal manipulation through the media. In some countries like the USA, subliminal messages are still poorly regulated. Thus, corporations have greater freedom of their usage. In Croatia, the Electronic Law has been passed by the media, which prohibits their use and states that commercial audiovisual communication must not use subconscious techniques. The Electronic Media Act enacts three important prohibitive laws to use and insert any subliminal and hidden messages, symbols, or sound. The law says that commercial audiovisual communication must be immediately recognizable as such. To conclude, a subject restricted or prohibited by law should be approached with caution from both, producers, and consumers. Based on these findings, it can be concluded that consumers are aware of subliminal messages, they believe advertisers frequently use them, and they think subliminal messages influence their behaviour. It seems like nothing has changed over the decades except the media types and frequency of their usage. The size of the sample and the data collection method were limitations in the study as well as the lack of complex scientific approach. It should also be noted that the attitudes are highly subjective category, and as for most attitude tests, scales are used to achieve unified responses so often, nor does it gain insight into the complete attitude of each respondent. The measuring instrument used for this paper was a survey questionnaire. However, it is recommended to use an in-depth interview or projective techniques since this is a sensitive topic and respondents may not be ready to express their opinion honestly. Therefore, the future researchers should continue to examine consumers' attitudes towards subliminal messages, and a possible desire of marketing managers to use this form of advertising more often, and the potential removal of restrictions on such and similar forms of advertising.

\section{REFERENCES}

Ayrapetova, A. G., 2020. Indoctrination is a mechanism of psychological manipulation in the process of involvement in destructive religious organizations. European Journal of Research and Reflection in Educational Sciences Vol, 8(11).

Ben-Aaron, M., 1975. The Pötzl effect: corroboration of a cybernetic hypothesis. https://doi.org/ 10.1080/01969727508546087

Bargh, J.A. and Pietromonaco, P., 1982. Automatic information processing and social perception: the influence of trait information presented outside of conscious awareness on impression formation. Journal of personality and Social psychology, 43(3), p.437. https://doi.org/10.1037/0022-3514.43.3.437

Benes, K.M., Gutkin, T.B. and Decker, T.N., 1990. The effects of mellow and frenetic music on reported cognitions resulting from auditory subliminal messages. The Journal of general psychology, 117(1), pp.83-89. https://doi.org/10.1080/00221309.1990.9917775

Benoit, S. C. \& Thomas, R. L. (1992). The influence of expectancy in subliminal perception experiments. Journal of General Psychology, 119(4), 335-341. https://doi.org/10.1080/00221309.1992.9921176

Bornstein, R. F., Leone, D. R., Galley, D. J., 1987. The generalizability of subliminal mere exposure effects: Influence of stimuli perceived without awareness on social behaviour. Journal of personality and social psychology, 53(6), 1070. https://doi.org/10.1037/0022-3514.53.6.1070

Crandall, K. B., 2006. Invisible commercials and hidden persuaders: James M. Vicary and the subliminal advertising controversy of 1957. Undergraduate Honors Thesis. The University of Florida. Available at http://plaza. ufl. edu/cyllek/docs/KCrandall_Thesis2006.pdf.

Dijksterhuis, A., Aarts, H. and Smith, P.K., 2005. The power of the subliminal: On subliminal persuasion and other potential applications. The new unconscious, 1, pp.77-106. https://doi.org/10.1093/ acprof:oso/9780195307696.003.0005 
Egermann, H., Kopiez, R. and Reuter, C., 2006. Is there an effect of subliminal messages in music on choice behavior?. Journal of Articles in Support of the Null Hypothesis, 4(2).

Froufe \& Schwartz, A. B. (2001). Subliminal messages for increasing self-esteem: placebo effect. Spanish Journal of Psychology, 4(1), 19-25. https://doi.org/10.1017/S1138741600005618

Gibson, B., Zielaskowski, K., 2013. Subliminal priming of winning images prompts increased betting in slot machine play. Journal of Applied Social Psychology, 43(1), pp. 106-115. https://doi.org/10.1111/j.1559-1816.2012.00985.x

Greenwald, A.G., Spangenberg, E.R., Pratkanis, A.R. and Eskenazi, J., 1991. Double-blind tests of subliminal self-help audiotapes. Psychological Science, 2(2), pp.119-122. https://doi.org/10.1111/j.1467-9280.1991.tb00112.x

Haber, R. N. (1959). Public attitudes regarding subliminal advertising. Public Opinion Quarterly, pp. 291-293. https://doi.org/10.1086/266875

Harris, J. L., Salus, D., Rerecich, R. \& Larsen, D. (1996). Distinguishing detection from identification in subliminal auditory perception: A review and critique of Merikle's study. Journal of General Psychology, 123(1), 41-50. https://doi.org/10.1080/00221309.1996.9921258

Hassin, R. R., Sklar, A. Y., 2014. The Human Unconscious. Dual-Process Theories of the Social Mind, 299.

Henley, S., 1975. Cross-modal effects of subliminal verbal stimuli. Scandinavian Journal of Psychology, 16(1), pp.30-36. https://doi.org/10.1111/j.1467-9450.1975.tb00160.x

Karremans, J. C., Stroebe, W., Claus, J., 2006. Beyond Vicary's fantasies: The impact of subliminal priming and brand choice. Journal of experimental social psychology, 42(6), pp. 792-798. https://doi.org/ 10.1016/j.jesp.2005.12.002

Key, W. B., 1992. The age of manipulation: The con in confidence, the sin insincere. Madison books.

Krosnick, J. A., Betz, A. L., Jussim, L. J., Lynn, A. R., 1992. Subliminal conditioning of attitudes. Personality and Social Psychology Bulletin, 18(2), pp. 152-162. https://doi.org/10.1177/0146167292182006

Libet, B., Alberts, W. W., Wright, E. W., Delattre, L. D., Levin, G., Feinstein, B., 1964. Production of threshold levels of conscious sensation by electrical stimulation of the human somatosensory cortex. Journal of Neurophysiology, 27, pp. 546-578. https://doi.org/10.1152/jn.1964.27.4.546

Merikle, P. M. \& Skanes, H. E. (1992). Subliminal self-help audiotapes: A search for placebo effects. Journal of Applied Psychology, 77(5), 772-776. https://doi.org/10.1037/0021-9010.77.5.772

Miliša, Z., Nikolić, G., 2013. Subliminalne poruke i tehnike u medijima. Istraživački medijski centar-Podgorica, 199.

Millar, M. M., O'Neill, A. C., Dillman, D. A. (2009). Are mode preferences real? Pullman: Washington State University, 9, pp. 2-41.

Mitchell. (1995). Effects of subliminally presented auditory suggestions of itching on scratching behavior. Perceptual and Motor Skills, 80(1), 87-96. https://doi.org/10.2466/pms.1995.80.1.87

Moore, T. E. (1995). Subliminal self-help auditory tapes: an empirical test of perceptual consequences. Canadian Journal of Behavioural Science, 27(1), 9-20. https://doi.org/10.1037/008-400X.27.1.9

Möller, A. T., Kotzé, H. F. \& Sieberhagen, K. J. (1993). Comparison of the effects of auditory subliminal stimulation and rational-emotive therapy, separately and combined, on self-concept. Psychological Reports, 72(1), 131-145. https://doi.org/10.2466/pro.1993.72.1.131

Moore, T. E., 1982. Subliminal advertising: What you see is what you get. Journal of Marketing, 46(2), pp. 3847. https://doi.org/10.1177/002224298204600205

Mulder, J., de Bruijne, M., 2019. The willingness of online respondents to participate in alternative modes of data collection. Survey Practice, 12(1), 8356. https://doi.org/10.29115/SP-2019-0001

Riggs, L. A., Volkmann, F. C., Moore, R. K., Ellicott, A. G., 1982. Perception of suprathreshold stimuli during saccadic eye movement. Vision Research, 22(4), pp. 423-428. https://doi.org/10.1016/0042-6989(82)90187-0

Russell, T. G., Rowe, W. \& Smouse, A. D. (1991). Subliminal self-help tapes and academic achievement: an evaluation. Journal of Counseling \& Development, 69(4), 359-362. https://doi.org/10.1002/j.1556-6676.1991.tb01522.x

Schiffman, L. G., Kanuk, L. L., Fridl, M., 2004. Ponašanje potrošača. Mate. 
Sigman, A., 2012. Time for a view on screen time. Archives of disease in childhood, 97 (11), pp. $935-942$. https://doi.org/10.1136/archdischild-2012-302196

Smyth, J. D., Olson, K., Millar, M. M., 2014. Identifying predictors of survey mode preference. Social science research, 48, pp. 135-144. https://doi.org/10.1016/j.ssresearch.2014.06.002

Staum, M. J. \& Brotons, M. (1992). The influence of auditory subliminals on behavior: a series of investigations. Journal of Music Therapy, 29(3), 130-185. https://doi.org/10.1093/jmt/29.3.130

Strahan, E. J., Spencer, S. J., Zanna, M. P., 2002. Subliminal priming and persuasion: Striking while the iron is hot. Journal of experimental social psychology, 38(6), pp. 556-568. https://doi.org/10.1016/S0022-1031(02)00502-4

Theus, K. T., 1994. Subliminal advertising and the psychology of processing unconscious stimuli: A review of research. Psychology \& Marketing, 11(3), pp. 271-290. https://doi.org/10.1002/mar.4220110306

Tolić, M., Vertovšek, N., Miliša, Z., 2009. Mediji i mladi: prevencija ovisnosti o medijskoj manipulaciji.

Towers, I., Duxbury, L., Higgins, C., Thomas, J., 2006. Time thieves and space invaders: Technology, work and the organization. Journal of Organizational Change Management. https://doi.org/10.1108/09534810610686076

Twenge, J. M., Martin, G. N., Campbell, W. K., 2018. Decreases in psychological well-being among American adolescents after 2012 and links to screen time during the rise of smartphone technology. Emotion, 18(6), 765. https://doi.org/10.1037/emo0000403

Van der Voort, T. H., Beentjes, J. W., Bovill, M., Gaskell, G., Koolstra, C. M., Livingstone, S., Marseille, N., 1998. Young people's ownership and uses of new and old forms of media in Britain and the Netherlands. European Journal of Communication, 13 (4), pp. 457-477. https://doi.org/10.1177/0267323198013004002

Vokey, J. R., Read, J. D., 1985. Subliminal messages: Between the devil and the media. American Psychologist, 40 (11). https://doi.org/10.1037/0003-066X.40.11.1231

Walls, K. C., Taylor, J. A. \& Falzone, J. (1992). The effects of subliminal suggestions and music experience on the perception of tempo in music. Journal of Music Therapy, 29(3), 186-197. https://doi.org/10.1093/jmt/29.3.186

Weber, R., 2010. Implement Purchase Choice into the Customer. Retrieved February, Vol. 12, 2014.

Zanot, E. J., Pincus, J. D., Lamp, E. J., 1983. Public perceptions of subliminal advertising. Journal of Advertising, 12 (1), pp. 39-45. https://doi.org/10.1080/00913367.1983.10672829 
Appendix: The online questionnaire

1. Please specify your gender:

male

female

2. Please specify your age:

$15-24$

$25-34$

$35-44$

$45-54$

55 and older

3. What is the highest degree or level of school you have completed? If currently enrolled, highest degree received:

primary school

secondary school

university degree, and more

4. Please select all types of media which you regularly consume:

television

radio

video games

newspapers

magazines

films

Web / Internet

other:

5. Do you ever consciously feel influenced by adverts?

yes

no

not sure

After this question, respondents were asked to click on the link to watch the video explaining what the subliminal messages are: https://youtu.be/UHH7zJySTrw (video duration 3,47 min)

6. Before accessing this website, have you heard of subliminal advertising before?

I have heard of subliminal advertising before

I have not heard of subliminal advertising before

7. Do you think subliminal messages have been used in advertising?

yes

no

not sure

8. Do you think subliminal messages are used in advertising today?

yes

no

not sure 
9. If Yes, how frequent do you think the use of subliminal advertising is? Please move on to the next question if you did not answer yes.

Very rare 12345 Extremely frequent

10. Do you think subliminal advertising is an ethical or unethical practice? ethical unethical not sure

11. If you were watching a television programme and were aware that subliminal messages were embedded in the advertisements, would you continue watching?

This does not mean you can consciously see the messages; instead, you are aware they are present. Yes, I would continue watching

No, I would stop watching

12. To what degree do you think subliminal messages can affect people's attitudes or beliefs? No affect 12345 Significant affect

13. To what degree do you think subliminal messages can affect people's behaviour? No affect 12345 Significant affect 